\title{
Learning Nursing Ethics - Experience of Students of Dhaka Nursing College, Bangladesh
}

\author{
Nurunnabi $\mathrm{ASM}^{1}$
}

\begin{abstract}
Nursing ethics is taught in the subject 'Fundamentals of Nursing' in BSc Nursing curriculum in Bangladesh. The present study aims to examine nurse students' opinion regarding their learning nursing ethics. A total of 183 nursing students of Dhaka Nursing College, Bangladesh, from 1st year and 2nd year of BSc in Nursing course participated in this study, which was done between July and September, 2011. A semi-structured questionnaire was given to them. Besides mentioning their age, sex, socio-economic status, the students were asked to provide information about their acquisition and application of knowledge on codes of ethics and an evaluation on faculties (23 items). Most of the students were from low socioeconomic condition ( $n=157,85.79 \%)$. Nursing students perceived that their educators' teaching of the statements of the codes was fairly extensive (ranged from $3.32 \pm 0.365$ to $3.59 \pm 0.923$ ). The highest scores dealt with the nurse-patient relationship, and the mission of nurses. Single items with highest scores highlighted confidentiality, alleviation of suffering, impartiality, support to patients and patients' family members, personal responsibility of her/his work and the quality of care as well as respect to human dignity and autonomy. The least taught statements concerned nurses and society and nursing as a profession. Single items with lowest scores dealt with nurses' professional competence, nurses' participation in discussion and decision-making. Students regarded their own knowledge of the code of ethics $(3.45 \pm 0.585)$ and their skills to apply in practice $(3.51 \pm 0.573)$ as average. Two-thirds of students $(n=122 ; 66.67 \%)$ assessed their educators' knowledge as fully or almost adequate to teach, $15.85 \%(n=29)$ of the students assessed the knowledge as less adequate, and $17.48 \%$ $(n=32)$ could not assess it. Studying nursing students' opinions on learning nursing ethics would be a useful guide for the formation of their professional role as well as their education and training.
\end{abstract}

CBMJ 2019 January: vol. 08 no. 01 P: 30-34

Key words: Nursing ethics, fundamentals of nursing, nursing education, students' opinion.

\section{Introduction}

The code of ethics for nurses arises from within the long, distinguished,and enduring moral tradition of modern nursing across the globe. ${ }^{1}$ It isfoundational to nursing theory, practice, and praxis in its expression of the values, virtues and obligations that shape, guide, and inform nursing as a profession. ${ }^{1,2}$ Nursing ethics is taught in the subject 'Fundamentals of Nursing' in the first and second year of BSc in Nursing curriculum in Bangladesh. ${ }^{3}$ In the first year, modules include introduction and conceptual bases of nursing: nurses' roles and competencies required in promoting, maintaining, and restoring health; nursing process; theories and models of nursing; cultural \& ethical aspects of nursing; nurses' ethical behaviour, nursing self-management \& nursing care delivery within health care system; patient safety as well as introduction to interpersonal communication in nursing; assertive communication; interpersonal and therapeutic relationship; key elements inbuilding relationships; barriers to effective communication; communicating with other health care professionals; enhancing interpersonal communication skills. $^{3}$ In the second year, modules include ethics in nursing: concepts of a nurse, code of

1. Dr. Abu Sadat Mohammad Nurunnabi, Erasmus Mundus Master of Bioethics Student, Centre for Biomedical Ethics and Law, Katholieke Universiteit Leuven, Belgium.

Address of correspondence:

Email:shekhor19@yahoo.com 
ethics, ethical principles, legal issues in nursing \& law, nursing regulations, bioethical issues; and professional standards; professional accountability; trends and issues in nursing: trans-cultural nursing; the process of educating nurses; transition from student to professional; different nursing organizations; and position of nurses. ${ }^{3}$ The code of ethics for nurses addresses individuals well as collective nursing intentions and requires each nurse to demonstrate ethical competence in professional life. ${ }^{4}$ Hence, the teaching of ethics in nursing education has become increasingly important in recent years. ${ }^{2}$ Despite the availability of a lot of literature about ethics education, there still is much debate among nursing educators concerning the best ways to teach ethics to nursing students, so that they can respond fully to ethical issues arising in their professional practice. ${ }^{4}$ The code of ethics is regarded as an essential content in most nursing ethics curricula. ${ }^{1,5}$ However, very little is known about how their teaching is implemented in a low resource country like Bangladesh. ${ }^{6}$ A reflection of students' opinion on their ethics education to the development of ethical competence can help develop good practices in ethics teaching. Hence, the present study aims to examine nurse students' opinion regarding their classroom learning of nursing ethics through didactic lectures.

\section{Materials and Methods:}

This cross-sectional study was done in Dhaka Nursing College, Bangladesh, which is the best nursing institution in the country. A total of 183 nursing students from 1st year and 2nd year of BSc in Nursing course voluntarily participated in this study, which was done between July and September, 2011. A semi-structured questionnaire was given to them. Besides mentioning their age, sex, socio-economic status, the students were asked to provide information about their acquisition and application of knowledge on codes of ethics and an evaluation on faculties (23 items). A 5-point Likert scale used in the survey. A Likert scale assumes that the strength/intensity of an attitude is linear, i.e. on a continuum from strongly disagree to strongly agree (ranging from 1 to 5 ) and each of the five responses has a numerical value which was used to measure the attitude under investigation. ${ }^{7,8}$ Moreover, by offering an anonymity on self-administered questionnaires should further reduce social pressure, and thus may like wise reduce social desirability bias. ${ }^{8}$

Declaration of Helsinki and its later amendments or comparable ethical standards were followed wherever applicable. As the research did not involve human participants, it was approved by the administration of Dhaka Nursing College, Dhaka, Bangladesh. Informed consents were obtained from all the participants. All participants had been provided an explanation about this data that it would never be used for any other purpose other than for this research. All the information was treated confidentially and anonymously.

\section{Results:}

Most of the students were from low socioeconomic condition ( $n=157, \quad 85.79 \%)$ (Table-I). Nursing students perceived that their educators' teaching of the statements of the codes was fairly extensive (ranged from $3.32 \pm 0.365$ to $3.59 \pm 0.923$ ) (Table-II). The highest scores dealt with the nursepatient relationship, and the mission of nurses. Single items with highest scores highlighted confidentiality, then alleviation of suffering, impartiality, support to patients and patients' family members, personal responsibility of her/his work and the quality of care as well as respect to human dignity and autonomy (Table-III).

The least taught statements concerned nurses and society and nursing as a profession. Single items with lowest scores dealt with nurses' professional competence, nurses' participation in discussion and decision-making (TableIII). Students regarded their own knowledge of the code of ethics (3.45 \pm 0.585$)$ and their skills to apply in practice $(3.51 \pm 0.573)$ as average (TableIV). 
Two-thirds of students ( $n=122 ; 66.67 \%)$ assessed their educators' knowledge as fully or almost adequate to teach, $15.85 \%$ $(n=29)$ of the students assessed the knowledge as less adequate, and $17.48 \%$ $(n=32)$ could not assess it (Table-V).

Table-I: Socio demographic characteristics of the participants $(n=183)$

\begin{tabular}{|l|c|c|}
\hline \multicolumn{1}{|c|}{$\begin{array}{c}\text { Socio demographic } \\
\text { Characteristics }\end{array}$} & Number & Percentage \\
\hline Sex & & \\
\hline Male & 12 & 6.56 \\
\hline Female & 171 & 93.44 \\
\hline Habitant & & \\
\hline Rural & 134 & 73.22 \\
\hline Semi-urban & 38 & 20.77 \\
\hline Urban & 11 & 6.01 \\
\hline Family income & & \\
\hline Low (less than 100,000 BDT per annum) & 147 & 80.33 \\
\hline Middle (100,000 - 300,000 BDT per annum) & 23 & 12.57 \\
\hline High (more than 300,000 BDT per annum) & 13 & 7.10 \\
\hline
\end{tabular}

Table-II: Topics in Ethics Education (based on 5-point Likert scale)

\begin{tabular}{|l|c|}
\hline Topic & Mean \pm SD \\
\hline Nurse-patient relationship & $3.59 \pm 0.923$ \\
\hline Mission of nurses & $3.58 \pm 0.237$ \\
\hline Nursing as a profession & $3.36 \pm 0.231$ \\
\hline Nurses and society & $3.32 \pm 0.365$ \\
\hline
\end{tabular}

Table-III: Specific Topics in Ethics Education and Competence (based on 5point Likert scale)

\begin{tabular}{|l|l|}
\hline Specific Topic & Mean \pm SD \\
\hline Confidentiality & $4.69 \pm 0.223$ \\
\hline Alleviation of suffering & $4.63 \pm 0.235$ \\
\hline Impartiality & $4.59 \pm 0.283$ \\
\hline $\begin{array}{l}\text { Support to patients and patients' } \\
\text { family members }\end{array}$ & $4.43 \pm 0.243$ \\
\hline Personal responsibility & $4.42 \pm 0.226$ \\
\hline Quality of care & $4.42 \pm 0.126$ \\
\hline Respect to human dignity and autonomy & $4.42 \pm 0.076$ \\
\hline Professional competence & $2.05 \pm 0.043$ \\
\hline $\begin{array}{l}\text { Nurses' participation in discussion and } \\
\text { decision-making }\end{array}$ & $1.29 \pm 0.017$ \\
\hline
\end{tabular}

Table-IV: Survey on Learning Nursing Ethics (based on 5-point Likert scale)

\begin{tabular}{|l|c|}
\hline Specific Topic & Mean \pm SD \\
\hline Student's own knowledge & $3.45 \pm 0.585$ \\
\hline Student's own skill to practice & $3.51 \pm 0.573$ \\
\hline $\begin{array}{l}\text { Student's personal development } \\
\text { (ethics in person and profession) }\end{array}$ & $3.41 \pm 0.261$ \\
\hline Student's own ethical decision-making capacity & $2.81 \pm 0.438$ \\
\hline
\end{tabular}

Table-V: Survey on Teaching Nursing Ethics (based on 5-point Likert scale)

\begin{tabular}{|l|c|}
\hline Competence of the instructor & Students agreed \\
\hline Fully adequate & $122(66.67 \%)$ \\
\hline Less adequate & $29(15.85 \%)$ \\
\hline Could not assess & $32(17.48 \%)$ \\
\hline
\end{tabular}

\section{Discussion}

Individuals who become nurses, as well as the professional organizations that represent them, are expected not only to adhere to the values, moral norms, and ideals of the profession but also to embrace them as a part of what it means to be a nurse. ${ }^{2,5}$ The ethical tradition of nursing is self-reflective, enduring, and distinctive. ${ }^{4}$ A code of ethics for the nursing profession makes explicit the primary obligations, values, and ideals of the profession that inform every aspect of the nurse's life. Nurse educators very often face the challenge of deciding whether ethics education is best addressed through ethics specific courses or through ethics lectures integrated throughout the curriculum, or by teaching abstract theories or by using more skillsbased approaches, through lectures, or by stressing clinical experience and reflection. ${ }^{9-11}$ However, Grady et al. ${ }^{12}$ found that approximately $22.7 \%$ of nurses in their study reported no ethics education and only slightly more than half $(51.2 \%)$ had ethics course work in their basic and/or advanced professional program. Similar to the present study, students argued that ethics education contributed to the ethical reflection and competence in several other studies. ${ }^{13-15}$ Through ethics education, students became aware of their personal qualities and limitations and they discovered personal and 
professional values and they could state their thoughts positively, and could conceive counter arguments. ${ }^{11,14,15}$ Students perceived teaching of the codes as fairly extensive. The most emphasis was on the nurse-patient relationship. However, evidence showed that even in developed countries, when faced with a micro ethical issue i.e. "the everyday ethical decisions that practicing nurses make in the context of common or routine clinical situations" ${ }^{16}$, specifically decisionmaking around safe medication administration, participants struggled to recall and deliberately apply ethics principles. ${ }^{16}$ Besides, educators' use of teaching and evaluation methods was narrow, as described in some other similar studies. Students whose teaching had been integrated into clinical training perceived that teaching had been more extensive. However, students did not perceive integration to clinical training as a much used teaching format. Most of the students assessed their own knowledge and ability to apply the codes as neutral, which is similar to the findings of Numminen et al. ${ }^{17}$ It is also assumed that those educators, whose knowledge about the codes students had assessed as adequate, were also perceived to teach the codes more extensively, as evident in similar other research. ${ }^{13,14,17}$

In this research, nursing students' attitudes related to their ethics education was conducted through semi-structured questionnaires. However, it limits the understanding individual subjectivity. Moreover, like all surveys, the validity of the Likert scale attitude measurement can be compromised due to social desirability, which means that individuals may lie to put themselves in a positive light. The participants were assured of confidentiality of their responses to minimize this type of phenomenon. Another limitation of this study is the results have to be carefully applied to other cases, especially in Western society, because the participants of this study are limited to Bangladeshi nursing students, who pursuit their education in a low-resource setting.

\section{Conclusion}

Studying nursing students' opinions on their learning nursing ethics would be a useful guide for the formation of their professional role as well as their education and training. Regardless of the responding students' positive description of the teaching, the findings should be interpreted with caution, due to the students' limited interest to respond. This study was a modest effort to find out student's satisfaction on their classroom teaching. Hence, more research are recommended with larger samples and by comparing performance between classroom and clinical settings. In teaching ethics, particular attention should be paid to teaching and evaluation methods, educators' competence in ethics, and student outcomes especially in clinical settings.

\section{References:}

1. Gallagher $A$. The teaching of nursing ethics:content and method. In: Davis $A$, Tschudin V, De Raeve L. (eds). Essentials of teaching and learning in nursing ethics: perspectives and methods. London: Churchill Livingstone; 2006: 223-39.

2. Fry ST. Teaching ethics in nursing curricula.Traditional and contemporary models. Nurs Clin North Am. 1989;24(2):485-97.

3. Bangladesh Nursing Council. Curriculum for B.Sc. in Nursing 2006. Dhaka: Directorate of Nursing Services, Ministry of Health and Family Welfare, Bangladesh; 2007.

4. Cannaerts N, Gastmans C, Dierckx de Casterle B. Contribution of ethics education to the ethical competence of nursing students: educators' and students' perceptions. Nurs Ethics. 2014;21(8):86178

5. Thompson JE, Thompson HO. Teaching ethics to nursing students. Nurs Outlook. 1989;37(2):84-8.

6. Begum H. Healthcare, ethics and nursing in Bangladesh: a personal perspective. Nurs Ethics. 1998;5(6):535-41.

7. Santina M, Perez J. Health professionals' sex and attitudes of health science students to health claims. Med Educ. 2003;37(6):509-13. 
8. Hansen JP. CAN'T MISS - conquerany number task by making important statistics simple. Part 1.Types of variables, mean, median, variance and standard deviation.J Health Care Qual.2003;25 (4):19-24.

9. Dinc L, Gorgulu RS. Teaching ethics in nursing. Nurs Ethics. 2002;9(3):259-68.

10. Woods M. Nursing ethics education: are we really delivering the good(s)? Nurs Ethics. 2005;12(1):5-18.

11. Numminen $O$, van der Arend A, Leino-Kilpi $H$. Nurse educators' and nursing students' perspectives on teaching codes of ethics. Nurs Ethics. 2009;16(1):69-82.

12. Grady C, Danis M, Soeken KL, O'Donnell $P$, Taylor C, Farrar A, Ulrich CM. Does ethics education influence the moral action of practicing nurses and social workers? Am J Bioeth. 2008;8(4):4-11.

13. Kalaitzidis E, Schmitz K. A study of an ethics education topic for undergraduate nursing students. Nurse Educ Today. 2012;32(1):111-5.

14. Lin CF, Lu MS, Chung CC, Yang CM. A comparison of problem-based learning and conventional teaching in nursing ethics education. Nurs Ethics. 2010;17(3): 37382.

15. Doane G, Pauly B, Brown H, McPherson $G$. Exploring the heart of ethical nursing practice: implications for ethics education. Nurs Ethics. 2004;11(3):240-53.

16. Krautscheid L, Brown M. Microethical decision making among baccalaureate nursing students: a qualitative investigation. $J$ Nurs Educ. 2014;53(3):S19-25.

17. Numminen $\mathrm{OH}$, Leino-Kilpi $\mathrm{H}$, van der Arend A, Katajisto J. Nursing students and teaching of codes of ethics: an empirical research study. IntNurs Rev. 2009;56(4):483-90. 